\title{
Nationwide prevalence and incidence study of neuromyelitis optica spectrum disorder in Denmark
}

Viktoria Papp, MD, Zsolt Illes, MD, PhD, Melinda Magyari, MD, PhD, Nils Koch-Henriksen, MD, PhD, Matthias Kant, MD, PhD, Claudia Christina Pfleger, MD, PhD, Shanu Faerch Roemer, MD, PhD, Michael Broksgaard Jensen, MD, PhD, Annett Evelyn Petersen, MD, Helle Hvilsted Nielsen, MD, PhD, Lene Rosendahl, MD, Zsolt Mezei, MD, PhD, Tove Christensen, PhD, Kristina Svendsen, MD, PhD, Poul Erik Hyldgaard Jensen, MD, PhD, Magnus Christian Lydolph, MD, PhD, Niels Heegaard, MD, PhD, Jette Lautrup Frederiksen, MD, PhD, Finn Sellebjerg, MD, PhD, Egon Stenager, MD, PhD, and Thor Petersen, MD, PhD

Neurology ${ }^{\circledR}$ 2018;91:e2265-e2275. doi:10.1212/WNL.0000000000006645

\section{Abstract}

\section{Objectives}

To estimate the nationwide population-based incidence, prevalence, and geographical distribution of neuromyelitis optica (NMO) spectrum disorder (NMOSD) in Denmark based on the 2015 International Panel for NMO Diagnosis (IPND) criteria.

\section{Methods}

We conducted a multicentre, historically prospective study. Data were sourced from the Danish National Patient Registry, the Danish Multiple Sclerosis Registry, departments of neurology, and laboratories providing aquaporin-4 antibody test. Cases were selected based on the 2006 Wingerchuk and the 2015 IPND criteria and were individually validated by an expert panel.

\section{Results}

We confirmed NMO in 30 cases (2006 criteria) and NMOSD in 56 cases (2015 IPND criteria) between 2007 and 2014. Defined by the 2006 criteria, the incidence of NMO was 0.029 per 100,000 person-years (95\% confidence interval [CI] 0.014-0.051), and the prevalence (aged 16 years and older) was 0.566 per 100,000 (95\% CI $0.370-0.830)$. Based on the 2015 IPND criteria, the incidence of NMOSD was 0.070 per 100,000 person-years (95\% CI 0.046-0.102), and the prevalence (aged 16 years and older) was 1.09 per 100,000 (95\% CI 0.808-1.440), without regional differences.

\section{Conclusions}

Our estimates of incidence and prevalence are similar to other Caucasian population-based studies using the 2015 IPND criteria. We found no geographical clustering in Denmark.

\author{
Correspondence \\ Dr. Papp \\ papp.vittoria@gmail.com
}

From the Department of Neurology (V.P., K.S., T.P.), Aarhus University Hospital; Department of Neurology (Z.I., H.H.N.), Odense University Hospital; Institute of Clinical Research (Z.I., H.H.N.), Institute of Molecular Biology (H.H.N.), and Department of Regional Health Research, Faculty of Health Sciences (E.S.), University of Southern Denmark, Odense; The Danish Multiple Sclerosis Center (M.M., P.E.H.J., F.S.), Department of Neurology, Rigshospitalet, University of Copenhagen; The Danish Multiple Sclerosis Registry (M.M., N.K.-H.), Department of Neurology, Rigshospitalet, Copenhagen University Hospital; Department of Clinical Epidemiology, Clinical Institute (N.K.-H.), and Department of Biomedicine (T.C.), Aarhus University; MS-Clinic of Southern Jutland (Sønderborg, Esbjerg, Kolding) (M.K., E.S.), Department of Neurology, Hospital of Southern Jutland, Sønderborg; Department of Neurology (C.C.P., Z.M.), Aalborg University Hospital; Multiple Sclerosis Unit (S.F.R.), Department of Neurology, Herlev Hospital, Copenhagen; Department of Neurology (M.B.J.), Nordsjællands Hospital, Hillerød; Department of Neurology (A.E.P.), Hospital of Southwest Jutland, Esbjerg; Department of Neurology (L.R.), Hospital of Central Denmark Region, Viborg; Department of Autoimmunology and Biomarkers (M.C.L., N.H.), Statens Serum Institut, Copenhagen; and Department of Neurology (J.L.F.), Rigshospitalet Glostrup, Faculty of Health and Medical Sciences, University of Copenhagen, Glostrup, Denmark. 


\section{Glossary}

$\mathbf{A b}=$ antibody; $\mathbf{A Q P 4}=$ aquaporin-4; $\mathbf{C B A}=$ cell-based assay; $\mathbf{C I}=$ confidence interval; $\mathbf{D M T}=$ disease-modifying therapy; ICD-10 = International Classification of Diseases, Tenth Revision; IPND = International Panel for Neuromyelitis Optica Diagnosis; MOG = myelin oligodendrocyte glycoprotein; $\mathbf{M S}=$ multiple sclerosis; NMO = neuromyelitis optica; NMOSD = neuromyelitis optica spectrum disorder; $\mathbf{O N}$ = optic neuritis; $\mathbf{O U H}=$ Odense University Hospital; $\mathbf{R H}=$ Neuroimmunology Laboratory at the Danish Multiple Sclerosis Center, Rigshospitalet, University of Copenhagen; SSI = Statens Serum Institute; $\mathbf{T M}=$ transverse myelitis.

Neuromyelitis optica (NMO)/NMO spectrum disorder (NMOSD) is a chronic, recurrent, antibody $(\mathrm{Ab})$-mediated, inflammatory disease affecting distinct areas of the CNS. ${ }^{1}$ Since the recognition of aquaporin-4 (AQP4) $\mathrm{Ab},{ }^{2}$ different NMO/NMOSD classifications have been proposed. The term definite NMO was applied to describe longitudinally extensive transverse myelitis (TM) together with optic neuritis (ON) regardless of the presence of AQP4-Ab., The first definition of NMOSD was used to define the spatially limited syndromes of $\mathrm{AQP} 4-\mathrm{Ab}$-seropositive $\mathrm{ON}$ or longitudinally extensive TM. ${ }^{5}$ The 2015 International Panel for NMO Diagnosis (IPND) criteria made it possible to diagnose AQP4$\mathrm{Ab}$-seropositive NMOSD with at least 1 of the 6 core clinical symptoms. In AQP4-Ab-seronegative cases, at least 2 of the 6 core clinical features supported by MRI lesion are required, and one of the clinical features has to be 1 of the 3 most common clinical features (ON, TM, area postrema syndrome). ${ }^{6}$ Anti-myelin oligodendrocyte glycoprotein (MOG) Abs that target the oligodendrocytes may be detected in $\mathrm{AQP} 4-\mathrm{Ab}-$ seronegative NMOSD.

Previous epidemiologic studies are diverse in the size of the target population, the method of case ascertainment, and the AQP4-Ab measurement (table 1). There are only a few population-based epidemiologic NMOSD studies applying the 2015 IPND criteria. $^{8-13}$

The aim of this population-based study was to estimate the incidence and prevalence of NMOSD in the entire Danish adult population according to the 2006 Wingerchuk and the 2015 IPND criteria by utilizing comprehensive datasets, and to assess differences between the 5 Danish regions.

\section{Methods}

\section{Study design}

This Danish nationwide study is based on collaboration and data acquisition from all 14 neurologic departments with responsibility for the management of patients with immunemediated CNS disorders. The target population comprised all patients diagnosed with $\mathrm{NMO}, \mathrm{ON}, \mathrm{TM}$, multiple sclerosis (MS) with ON or TM as presenting symptom, or those tested for AQP4-Ab from January 1, 2007, to December 31, 2014. Data collection from these patients continued until July 1 , 2016. We estimated the prevalence of patients aged 16 years and older, because the registration of patients younger than age 16 at prevalence day would probably be incomplete, as we had no arrangements with the pediatric departments. However, patients with onset before age 16 were included in the incidence analysis because after diagnosis they are regularly followed up at the departments of neurology.

The entire Danish population has access to tax-funded, freeof-charge health care. Four specialized university hospitals (Aalborg, Aarhus, Odense, Rigshospitalet) are in charge of the clinical care of patients with NMOSD. Other departments are requested to refer all newly diagnosed patients with NMOSD to these centers.

\section{Sources}

Multiple sources were combined for the best coverage (figures 1 and 2):

1. The Danish National Patient Registry, established in 1977, has collected data on all admissions and outpatient visits since 1995. It includes information about the hospital department, admission and discharge dates, and discharge diagnoses, according to the ICD-10. ${ }^{14} \mathrm{We}$ included all patients registered with NMO/Devic disease (DG36.0), ON (DH46.9), and acute TM (DG37.3) between January 1, 2007, and December 31, 2014.

2. The Danish Multiple Sclerosis Registry has been collecting data on MS since $1948 .{ }^{15,16}$ All Danish citizens diagnosed with MS or suspected MS by a neurologist are notified in the Danish Multiple Sclerosis Registry and reclassified by an MS expert at the time of data entry, based on the medical records. Patients with MS who had $\mathrm{ON}$ or TM as the presenting symptom were reevaluated for possible NMO/NMOSD.

3. Laboratories providing $\mathrm{AQP} 4-\mathrm{Ab}$ detection tests in Denmark supplied the list of patients tested for this $\mathrm{Ab}$. These laboratories are the Statens Serum Institute (SSI), the Department of Clinical Immunology at Odense University Hospital (OUH), and the Neuroimmunology Laboratory at the Danish Multiple Sclerosis Center, Rigshospitalet, University of Copenhagen (RH). In total, 4,067 samples from 3,397 patients were tested within the study period.

4. All departments of neurology were asked to report any NMOSD and possible NMOSD cases.

To ensure the highest possible quality of data, we excluded patients who had never been seen at any public neurology departments or if crucial clinical information was missing. 


\begin{tabular}{|c|c|c|c|c|c|c|c|c|}
\hline Country & Population (million) & Source & Criteria & AQP4 test & $\begin{array}{l}\text { Incidence/ } \\
100,000\end{array}$ & $\begin{array}{l}\text { Period of } \\
\text { incidence rate }\end{array}$ & $\begin{array}{l}\text { Prevalence/ } \\
100,000\end{array}$ & $\begin{array}{l}\text { Percentage of } \\
\text { seronegative cases }\end{array}$ \\
\hline \multicolumn{9}{|l|}{ Caucasian } \\
\hline $\begin{array}{l}\text { Southern Denmark } \\
\text { (Denmark) }^{24}\end{array}$ & 0.952 (age $\geq 15$ y) & $\begin{array}{l}\text { Multiple: registry, } \\
\text { department }\end{array}$ & $\begin{array}{l}2006 \text { seropositive ON/ } \\
\text { LETM }\end{array}$ & $\begin{array}{l}\text { CBA, } \\
\text { immunoprecipitation } \\
\text { assay }\end{array}$ & 0.4 & Not specified & 4.4 & 38 \\
\hline South East Wales (UK) ${ }^{25}$ & $0.713(\mathrm{FP})$ & $\begin{array}{l}\text { Multiple: registry, } \\
\text { laboratory, department }\end{array}$ & $\begin{array}{l}2006 \text { seropositive ON/ } \\
\text { LETM }\end{array}$ & Not reported & NA & NA & 1.96 & 28 \\
\hline $\begin{array}{l}\text { Northwest England } \\
(\text { (UK) })^{26}\end{array}$ & 1.14 (age >16 y) & $\begin{array}{l}\text { Multiple: registry, } \\
\text { laboratory, department }\end{array}$ & $\begin{array}{l}2006 \text { seropositive ON/ } \\
\text { LETM }\end{array}$ & CBA & 0.08 & $2003-2010$ & 0.72 & 12 \\
\hline Austria $^{23}$ & 8.4 (FP) & $\begin{array}{l}\text { Multiple: department, } \\
\text { laboratory }\end{array}$ & $\begin{array}{l}\text { Only AQP4-seropositive } \\
\text { NMO/NMOSD }\end{array}$ & CBA & 0.054 & $2008-2011$ & 0.7 & Not included \\
\hline $\begin{array}{l}\text { Isfahan Province } \\
(\text { (Iran) })^{32}\end{array}$ & Not specified & Single: registry & 2006 & Not specified & NA & NA & 1.9 & 33.7 \\
\hline Southwest Iran (Iran) ${ }^{31}$ & $4.5(\mathrm{FP})$ & $\begin{array}{l}\text { Multiple: department and } \\
\text { MS Society }\end{array}$ & $\begin{array}{l}2006 \text { seropositive } \\
\text { NMOSD }^{\mathrm{a}}\end{array}$ & Not specified & NA & NA & 1.1 & Not specified \\
\hline Olmsted County (MN) ${ }^{27}$ & $0.146(\mathrm{FP})$ & $\begin{array}{l}\text { Multiple: registry, } \\
\text { department }\end{array}$ & $\begin{array}{l}2006 \text { seropositive } \\
\text { NMOSD }^{\mathrm{a}}\end{array}$ & CBA & 0.07 & $2003-2011$ & 3.9 & 17 \\
\hline Tehran (Iran) $)^{12}$ & $1.2(\mathrm{FP})$ & Single: department & 2015 & ELISA & NA & NA & 0.86 & 53.2 \\
\hline $\begin{array}{l}\text { Australia and New } \\
\text { Zealand }^{8}\end{array}$ & 27.67 (FP) & $\begin{array}{l}\text { Multiple: department, } \\
\text { laboratory }\end{array}$ & 2015 & $\begin{array}{l}\text { CBA }(46 \%), \text { IF-tissue } \\
\text { assay }(100 \%)\end{array}$ & 0.037 & $2009-2012$ & 0.7 & 10 \\
\hline Catalonia (Spain) ${ }^{9}$ & 7.52 (FP) & $\begin{array}{l}\text { Multiple: registry, } \\
\text { laboratory, department }\end{array}$ & 2015 & $\begin{array}{l}\text { CBA (96\%), } \\
\text { immunohistochemistry } \\
(3 \%), \text { ELISA (1\%) }\end{array}$ & 0.063 & $2006-2016$ & 0.89 & 27 \\
\hline $\begin{array}{l}\text { Central Denmark } \\
\text { Region (Denmark) }{ }^{11}\end{array}$ & $1.27(\mathrm{FP})$ & Single: department & 2015 & ELISA, anti-AQP4 IIFT & 0.12 & $2012-2013$ & NA & Not specified \\
\hline \multicolumn{9}{|l|}{ Non-Caucasian } \\
\hline Cuba $^{28}$ & 11.18 (FP) & $\begin{array}{l}\text { Multiple: registry, } \\
\text { department }\end{array}$ & 2006 & Not specified & 0.053 & $2003-2004$ & 0.52 & Not specified \\
\hline $\begin{array}{l}\text { Tokachi Province } \\
\text { (Japan) }\end{array}$ & 0.352 (FP) & Single: department & 2006 & CBA & NA & NA & 0.9 & 0 \\
\hline Mangalore (India) ${ }^{30}$ & 0.419 (FP) & Single: department & $\begin{array}{l}2006 \text { seropositive ON/ } \\
\text { LETM }\end{array}$ & Not specified & NA & NA & 2.6 & Not specified \\
\hline
\end{tabular}


The minimum data required for seronegative NMOSD cases were clinical features and brain and spinal cord MRI once, respectively. For seropositive cases, clinical data and AQP4$\mathrm{Ab}$ seropositivity were required, but practically all patients had brain and spinal MRI at least once. We also excluded foreign citizens who had left Denmark.

\section{Case selection}

Medical records and MRIs of all patients from the abovementioned sources were reevaluated. The following information was included in the research dataset: age; age at onset; city of residence; family history; ethnicity; autoimmune comorbidities, history of all relapses; clinical course; response to immunosuppressive and immunomodulatory therapy; all available brain and spinal cord MRIs performed at the time of diagnosis and during follow-up; all $\mathrm{AQP} 4-\mathrm{Ab}$ results; method of $\mathrm{AQP} 4-\mathrm{Ab}$ test; visual-evoked potentials; spinal fluid examination (cell count, protein concentration, immunoglobulin G index, oligoclonal bands); presence of other autoantibodies; and the results of clinical examinations to exclude alternative diagnoses.

We selected patients with possible NMOSD who met one of the following criteria for further case validation: (1) at least one positive AQP4-Ab test result; (2) according to the medical records, treatment for NMOSD or diagnosis of NMOSD at any time; and (3) suspicion of NMOSD based on the 2015 IPND criteria. ${ }^{6}$

\section{Case validation}

The final validation of the selected cases was done by an expert panel (the coauthors F.S., Z.I., J.F., T.P., E.S.). This panel of 5 neurology professors with treating responsibility for patients with NMOSD in Denmark anonymously and independently reviewed the data of all patients who were enrolled during the selection. The expert panel assessed the complete dataset including the clinical, neuroimaging, and laboratory data during the reevaluation. All final diagnoses were reached by a consensus decision.

\section{AQP4- and MOG-Ab tests}

All patients who fulfilled the selection criteria were previously tested at least once for AQP4-Ab. Samples collected at diagnosis or when the tests became available were tested for $\mathrm{AQP} 4-\mathrm{Ab}$ in at least one of the following laboratories: Mayo Clinic (Rochester, MN); John Radcliffe Hospital (Oxford, UK), Seeling Labs (Karlsruhe, Germany), RH (Copenhagen, DK), SSI (Copenhagen, DK), and OUH (Odense, DK) (Mayo Clinic: tissue-based immunofluorescence assay; Oxford John Radcliffe Hospital: CBA [cell-based assay]; Seeling Labs: in vitro translation/immunoprecipitation assay; RH: ELISA kit [EA111/96; DLD Diagnostika GmbH, Hamburg, Germany]; SSI: CBA; OUH: CBA [EUROIMMUN, Luebeck, Germany]). The following is the proportion of the assays used for the AQP4 test: $79.5 \%$ were tested with CBA, $13.7 \%$ of the patients were tested only with immunoprecipitation assay, $6.8 \%$ were tested only with ELISA, and 1 typical NMOSD case was analyzed with only tissue-based assay. 


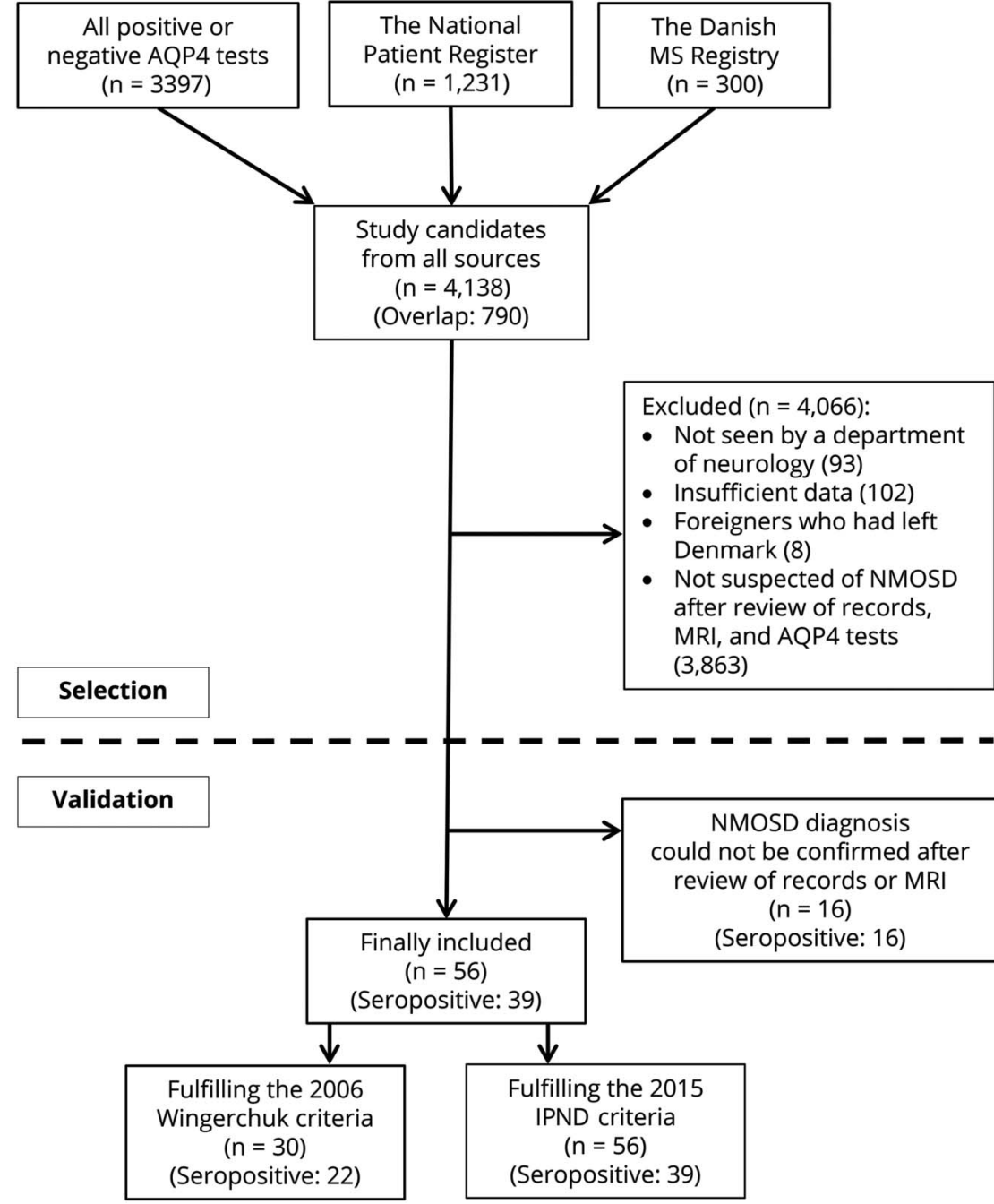

Flowchart demonstrates the strategy of patient selection and validation in the Danish population of age 16 years and older. $A Q P 4=$ aquaporin- 4 ; IPND = International Panel for Neuromyelitis Optica Diagnosis; MS = multiple sclerosis; NMOSD = neuromyelitis optica spectrum disorder.
At the SSI laboratory, the CBA for AQP4-Ab was validated by comparison with the CBA used at John Radcliffe Hospital, Oxford. The OUH laboratory uses the commercially available CBA (EUROIMMUN). After 5 years of experience interpreting the semiquantitative assay, $\mathrm{OUH}$ laboratory participated in a multicenter comparison study of AQP4 assays, with good results. ${ }^{17}$

In general, we took CBA performed in Oxford as a gold standard when it was done. In other cases, the result of the EUROIMMUN CBA (which is widely used) was considered, but when the clinical, laboratory, radiologic features, and the repeated inconsistent $\mathrm{AQP} 4-\mathrm{Ab}$ test result raised concern about the diagnosis of NMOSD, the case was reviewed by the expert panel. There were 429 patients tested with ELISA, and $46 \%$ of the same blood samples were retested with CBA in Oxford. In all of these cases, CBA was negative if the ELISA was negative. Samples from patients, in which there was a high clinical suspicion of NMOSD but ELISA screening was negative, were tested with CBA in Oxford. All samples positive with ELISA were also analyzed with CBA at John Radcliffe Hospital, Oxford.
The MOG Ab tests were undertaken by CBA at John Radcliffe Hospital, Oxford. ${ }^{18}$

\section{Statistical analysis}

Among the eventually included cases, we counted individuals notified from the laboratories as "captures" and individuals notified by the departments (either directly or through the National Patient Registry or MS Registry) as "recaptured." We used the Chapman ${ }^{19}$ estimator, which is regarded to be less biased with small sample sizes (figure 2).

The incidence and prevalence were estimated according to 2006 and 2015 criteria. ${ }^{3,6}$ We calculated incidence up to and including 2013 and prevalence for January 1, 2014, since ascertainment after this time may be incomplete because of the potential delay in diagnosis. The median time from the presenting symptom to the first relapse was up to 12 months in the Caucasian population, even in seropositive AQP4 cases. ${ }^{20}$ Incidence rates with the $95 \%$ confidence interval (CI) were calculated by using Poisson distribution from number of 
Figure 2 Sources of notification of the 56 included patients with neuromyelitis optica spectrum disorder

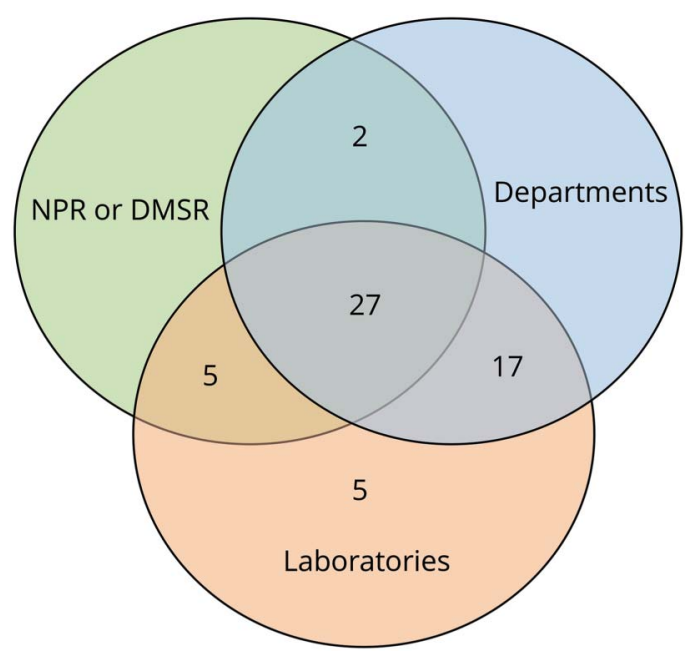

Venn diagram shows that we were able to identify all cases from the departments and laboratories. The NPR (National Patient Registry) and DMSR (Danish Multiple Sclerosis Registry) did not contribute with unique cases. Capture-recapture analysis requires that notification by a second source is independent of notification by the first source. Because both DMSR and NPR are strongly mutually dependent and also dependent with the departments, we treated them as a single source.

new-onset NMO/NMOSD cases between January 1, 2007, and December 31, 2013, and the full population number of person-years at risk 2007 through 2013 as denominator. Prevalence was determined by the number of patients with $\mathrm{NMO} / \mathrm{NMOSD}$ alive at age 16 years and older as numerator per 100,000 persons in the adult population (age 16 or older) as denominator. Quantitative variables are given as median and range. Data management and analyses were conducted using SPSS software (version 22; IBM Corp., Armonk, NY) and Excel Visual Basic (Microsoft, Redmond, WA).

\section{Standard protocol approvals, registrations, and patient consents}

The study was approved by the Danish Data Protection Agency (J no. 1-16-02-658-15) and the local ethical committee (Ethical Committee for The Region of Central Jutland; J no. 1-10-72-346-15).

\section{Data availability}

Data were carefully documented in the methods and results sections. Data are also available from Dryad (appendix 1, doi. org/10.5061/dryad.369417f). Further anonymized data can be shared by request from any qualified investigator.

\section{Results}

\section{Patient selection and validation}

The Danish population aged 16 years and older was 4,590,391 (female: $50.74 \%$ ) on January 1, 2014, and included $95.2 \%$ of individuals born in Europe, 3.5\% in Asia, 0.8\% in Africa, and $0.5 \%$ in other countries. ${ }^{21}$
The combined sources had notified us of 4,138 persons to be screened for this NMO/NMOSD study. We identified 55 adult patients with at least one positive AQP4-Ab test performed with the suggested CBA. ${ }^{6}$ After excluding some cases at different steps of the screening and analysis process (see the study flowchart in figure 1), we had 56 patients with a confirmed diagnosis of NMOSD, according to the 2015 criteria, with onset within the study period between January 1, 2007, and December 31, 2014. Of those 56 patients, 30 also met the 2006 NMO criteria.

In the last step of validation, 16 patients were excluded (data available from Dryad, appendix 1, doi.org/10.5061/dryad. 369417f). These patients had AQP4-Ab positivity (at low level) by CBA; the subsequent samples were negative in 14 of the 16 cases. The final diagnoses of these patients were MS $(\mathrm{n}=13)$, monophasic idiopathic TM $(\mathrm{n}=1)$, monophasic mild ON $(n=1)$, and probable recurrent idiopathic ON $(n=1)$. Median number of red flags for NMOSD by Wingerchuk et al. ${ }^{6}$ was 6 in the 13 patients with a final diagnosis of MS (table 2). Seven of the 13 patients had been treated with disease-modifying therapy (DMT) and were stable. One patient stopped DMT and remained clinically stable. Another 3 patients had never been treated, and 2 patients had a progressive disease course despite DMT (data available from Dryad, appendix 1, doi.org/10.5061/dryad. 369417f).

The median age at disease onset was 35.5 years (range 5-76). Disease onset before the age of 16 years was recorded in 7 patients (12.5\%), and at older than 50 years in 19 patients (34\%). The median years of follow-up was 8 years (range 1-46).

The female/male ratio was 4.6:1. In the seropositive group, this ratio was $12: 1$ but only 1.3:1 in the seronegative NMOSD group (Fisher exact test, $p=0.0055$ ).

Regarding ethnical background, 50 patients (89.3\%) were Caucasians, 4 (7.1\%) Asians, 1 (1.8\%) was Arabian, and 1 (1.8\%) African.

Of the $17 \mathrm{AQP} 4-\mathrm{Ab}$-seronegative cases included, 9 (53\%) had MOG Abs, 2 (12\%) were double-seronegative, and 6 (35\%) were not tested for MOG Abs.

\section{Capture-recapture analysis}

Two-sample capture-recapture analysis estimated that the "true" number of cases should be 56.2 so that the completeness is almost unity. The upper $95 \%$ confidence limit was 57.1.

\section{Incidence and prevalence of NMO based on the 2006 criteria}

There were 11 incident cases over the period of 2007-2013 emerging from the background population observed for $38,449,668$ person-years. Hence, the NMO incidence was 0.0286 per 100,000 person-years ( $95 \%$ CI $0.0143-0.0512$ ). 
Table 2 Red flags for NMOSD in the low AQP4 antibody-positive patients with final diagnosis of multiple sclerosis

\begin{tabular}{|c|c|}
\hline & $\begin{array}{l}\text { Cases } \\
(n=13)\end{array}$ \\
\hline Follow-up, y, median (range) & $15(7-34)$ \\
\hline Seroconversion from positive to negative & $13(100)$ \\
\hline \multicolumn{2}{|l|}{ Red flags $^{a}$} \\
\hline \multicolumn{2}{|l|}{ 1. Clinical or laboratory features } \\
\hline Progressive clinical course & $4(30.8)$ \\
\hline Duration of relapse $<4 \mathrm{~h}$ or worsening $>4 \mathrm{wk}$ & $6(46.2)$ \\
\hline Partial transverse myelitis & $9(76.9)$ \\
\hline CSF oligoclonal bands $(n=12)$ & $11(91.7)$ \\
\hline $\begin{array}{l}\text { Comorbidities: sarcoidosis, cancer, } \\
\text { chronic infection }\end{array}$ & 0 \\
\hline \multicolumn{2}{|l|}{ 2. MRI features (brain and spinal cord) } \\
\hline Dawson fingers & $11(84.6)$ \\
\hline $\begin{array}{l}\text { Adjacent to lateral ventricles in the } \\
\text { inferior temporal lobe }\end{array}$ & $4(30.8)$ \\
\hline Juxtacortical lesion & $6(46.2)$ \\
\hline Cortical lesion & 0 \\
\hline Persistent gadolinium-enhancing brain lesion & 0 \\
\hline Spinal cord lesion shorter than 3 segments $(n=12)$ & $8(66.6)$ \\
\hline Peripheral spinal cord lesion $(n=9)$ & $8(88.9)$ \\
\hline Diffuse, indistinct T2 spinal cord lesion $(n=12)$ & $4(33.3)$ \\
\hline 3. No. of red flags, median (range) & $6(3-8)$ \\
\hline
\end{tabular}

Abbreviations: AQP4 = aquaporin-4; NMOSD: neuromyelitis optica spectrum disorder.

Data are $\mathrm{n}(\%)$ unless otherwise indicated.

${ }^{a}$ According to the 2015 International Panel for Neuromyelitis Optica Diagnosis criteria.

The prevalence analysis included 26 NMO alive cases and the Danish population at age 16 and older as $4,590,391$ by January 1, 2014, giving a national prevalence rate of 0.566 per 100,000 persons (95\% CI $0.370-0.830)$. Sex- and serologic status-specific incidence and prevalence rates are also shown in table 3 .

\section{Incidence and prevalence of NMOSD based on the 2015 IPND criteria}

We identified 27 patients with onset in the period 2007-2013, resulting in an incidence of NMOSD of 0.0702 per 100,000 person-years (95\% CI $0.0463-0.1022)$. Five of 56 patients died before the prevalence date and one had disease onset after January 1, 2014, leaving 50 patients at age 16 years and older. Hence, the prevalence rate was accordingly 1.09 per 100,000 persons ( $95 \%$ CI $0.808-1.440$ ). Further results of incidence and prevalence rates stratified by sex and serologic status are shown in table 3 .
Prevalence in the Caucasian population was 1.007 (95\% CI $0.732-1.35$ ) and it was 2.47 (95\% CI 0.674-6.33) in the Asian population.

By applying the 2015 criteria, the prevalence increased 1.9fold and incidence 2.4-fold compared to 2006 criteria. In 17 seropositive patients with one clinical core criterion and in 9 seronegative patients, NMOSD was diagnosed based only on the new criteria. ${ }^{6}$

\section{Prevalence of NMOSD based on 2015 IPND criteria in the Danish regions}

No statistically significant differences were found in the prevalence rates (per 100,000 persons) among the 5 Danish regions $(p=0.88)$ (table 4$)$.

\section{Discussion}

This Danish nationwide population-based study combining data from population-based disease registries, laboratories, and hospitals generates an incidence estimate of 0.070 per 100,000 person-years and a prevalence of 1.09 per 100,000 persons according to 2015 IPND criteria. In general, our data are in line with previous epidemiologic studies in Caucasian populations. We observed an equal distribution of patients with NMOSD among the 5 Danish regions.

When the prevalence and incidence of an uncommon chronic disease are estimated, certain conditions are required to gain reliable and generalizable results. The sample size and the duration of observation can be critical for the assessment of the epidemiologic features of these conditions. ${ }^{22}$

In Denmark, AQP4-Ab measurement became available in December 2007, and since then, a large number of patients were tested. Therefore, we only included patients with clinical onset from 2007 to the end of 2014 and with follow-up by July 1, 2016. This broad timeframe is helpful to ensure the accuracy of the given NMOSD diagnosis, to rule out alternative diagnoses, and to compensate for delay between onset and diagnosis.

The absolute number of Danish patients (3,397 patients) tested for AQP4-Ab is more than twice as many as in the Austrian study (1,557 patients) and 3 times more compared to the Catalonia study (1,187 patients)., ${ }^{9}$ This shows that AQP4 analysis was performed in a higher proportion of the population in Denmark compared to other countries.

The main characteristics of the previous studies are summarized in table 1 . Most of the available epidemiologic outcomes were estimated according to the 2006 Wingerchuk criteria. ${ }^{24-33}$ Many of these reports also included the limited form of AQP4seropositive ON and TM or seropositive NMOSD. ${ }^{24-27,29-31}$ Two studies conducted in Caucasian populations based on the 2015 criteria applied study design comparable to our study. 
Table 3 Incidence and prevalence of the Danish NMO/NMOSD population based on the 2015 IPND criteria and the 2006 Wingerchuk criteria also stratified by sex and serologic status

\begin{tabular}{|c|c|c|c|c|c|c|c|}
\hline & \multirow[b]{3}{*}{$\begin{array}{l}\text { Background } \\
\text { population } \\
\text { age } \geq 16 \text { y } \\
\text { (January 1, } \\
\text { 2014) }\end{array}$} & \multicolumn{3}{|c|}{2015 IPND criteria } & \multicolumn{3}{|c|}{2006 Wingerchuk criteria } \\
\hline & & \multicolumn{3}{|c|}{ Prevalence per 100,000} & \multicolumn{3}{|c|}{ Prevalence per 100,000} \\
\hline & & $\begin{array}{l}\text { Prevalent } \\
\text { cases } \\
\text { (January 1, } \\
\text { 2014) }\end{array}$ & Prevalence & $95 \% \mathrm{Cl}$ & $\begin{array}{l}\text { Prevalent } \\
\text { cases } \\
\text { (January 1, } \\
\text { 2014) }\end{array}$ & Prevalence & $95 \% \mathrm{Cl}$ \\
\hline All & $4,590,391$ & 50 & 1.090 & $0.808-1.440$ & 26 & 0.566 & $0.370-0.830$ \\
\hline Female & $2,329,255$ & 41 & 1.760 & $1.260-2.390$ & 23 & 0.987 & $0.670-1.480$ \\
\hline Male & $2,261,136$ & 9 & 0.398 & $0.180-0.760$ & 3 & 0.133 & $0.027-0.388$ \\
\hline AQP4 seropositive & $4,590,391$ & 35 & 0.762 & $0.531-1.060$ & 20 & 0.436 & $0.266-0.673$ \\
\hline AQP4 seronegative & $4,590,391$ & 15 & 0.327 & $0.180-0.540$ & 6 & 0.131 & $0.048-0.284$ \\
\hline $\begin{array}{l}\text { NMOSD without MOG- } \\
\text { seropositive cases }\end{array}$ & $4,590,391$ & 42 & 0.915 & $0.659-1.240$ & 23 & 0.501 & $0.318-0.752$ \\
\hline
\end{tabular}

\begin{tabular}{|c|c|c|c|c|c|c|c|}
\hline & \multirow{2}{*}{$\begin{array}{l}\text { Background } \\
\text { population } \\
\text { (person- } \\
\text { years) }\end{array}$} & \multicolumn{3}{|c|}{ Incidence per 100,000 person-years } & \multicolumn{3}{|c|}{ Incidence per 100,000 person-years } \\
\hline & & $\begin{array}{l}\text { Incident } \\
\text { cases } \\
(2007-2013)\end{array}$ & $\begin{array}{l}\text { Incidence } \\
\text { rate }\end{array}$ & $95 \% \mathrm{Cl}$ & $\begin{array}{l}\text { Incident } \\
\text { cases } \\
(2007-2013)\end{array}$ & $\begin{array}{l}\text { Incidence } \\
\text { rate }\end{array}$ & $95 \% \mathrm{Cl}$ \\
\hline All & $38,449,668$ & 27 & 0.0702 & $0.0463-0.1022$ & 11 & 0.0286 & $0.0143-0.0512$ \\
\hline Female & $19,328,899$ & 20 & 0.1035 & $0.0632-0.1598$ & 9 & 0.0466 & $0.0213-0.0884$ \\
\hline Male & $19,120,769$ & 7 & 0.0366 & $0.0147-0.0754$ & 2 & 0.0105 & $0.0013-0.0378$ \\
\hline AQP4 seropositive & $38,449,668$ & 18 & 0.0468 & $0.0277-0.0741$ & 8 & 0.0208 & $0.0090-0.0410$ \\
\hline AQP4 seronegative & $38,449,668$ & 9 & 0.0234 & $0.0107-0.0444$ & 3 & 0.0078 & $0.0016-0.0228$ \\
\hline $\begin{array}{l}\text { NMOSD without MOG- } \\
\text { seropositive cases }\end{array}$ & $38,449,668$ & 22 & 0.0572 & $0.0359-0.0866$ & 9 & 0.0234 & $0.0107-0.0444$ \\
\hline
\end{tabular}

Abbreviations: AQP4 = aquaporin-4; Cl = confidence interval; IPND = International Panel for Neuromyelitis Optica Diagnosis; MOG = myelin oligodendrocyte glycoprotein; NMO = neuromyelitis optica; NMOSD = neuromyelitis optica spectrum disorder.

These research groups also utilized multiple sources and performed CBA for AQP4 measurement in the majority of the cases similarly to this cohort. In the study from Australia/New Zealand with a population of 27.7 million, the prevalence of NMOSD was 0.7 , significantly lower than the 1.09 in our study. ${ }^{8}$ In the study conducted in the Catalonian population comprising a population of 7.5 million, the prevalence was 0.89 , which corresponds well to our results. ${ }^{9}$ The difference may have arisen from the fact that the 2 other studies included the whole population age range, while we restricted our analyses of prevalence to cases and population with age of 16 years and older. Indeed, NMOSD is rarer in children than in adults. ${ }^{9}$ We also identified more AQP4-seronegative patients in Denmark (Australia 10\% and Catalonia 27\% vs Denmark

Table 4 Prevalence of neuromyelitis optica spectrum disorder according to the 2015 International Panel for Neuromyelitis Optica Diagnosis criteria in the 5 Danish regions

\begin{tabular}{llllr}
\hline Region & Population age $\mathbf{1 6}$ y (January 1, 2014) & Prevalent cases (January 1, 2014) & Prevalence per 100,000 & $\mathbf{9 5 \%} \mathrm{Cl}$ \\
\hline Capital Region & $1,430,139$ & 17 & 1.19 & $0.69-1.90$ \\
\hline Region Zealand & 667,584 & 5 & 0.75 & $0.24-1.75$ \\
\hline Region of Southern Denmark & 980,386 & 11 & 1.12 & $0.56-2.01$ \\
\hline Central Denmark Region & $1,034,105$ & 11 & 1.06 & $0.53-1.90$ \\
\hline North Denmark Region & 478,177 & 6 & 1.25 & $0.46-2.73$ \\
\hline
\end{tabular}

Abbreviation: $\mathrm{Cl}=$ confidence interval. 
$30.3 \%)$. One-third (35\%) of the seronegative NMOSD cases in our study were retrospectively recognized based on the 2015 criteria.

An Iranian study estimated the prevalence defined only by the 2015 IPND criteria, but patients were identified from a single neurology center and AQP4-Abs were measured with ELISA. Their results disclosed one of the highest proportion of seronegative NMOSD cases (53\%) among the studies. ${ }^{12}$

There are 2 population-based studies that published higher prevalence compared to our work ${ }^{24,27}$ and also to recently published data. ${ }^{8,9}$ One of these from the Region of Southern Denmark showed the highest prevalence among the Caucasian population and it also reported the highest incidence among the available studies worldwide. ${ }^{24}$ In contrast to that study, our current work applied both criteria (2006 and 2015 criteria), included all patients with NMOSD from the entire country, and cases with uncertain diagnosis were reassessed by an expert panel. The present study reviewed all patients from Denmark who were tested for AQP4-Ab in the period of 2007-2014, also including the Region of Southern Denmark. Our incidence data are also supported by the recent Danish study from the Region of Central Jutland that found an incidence rate similar to our nationwide result. ${ }^{11}$ In the other recent study that reported similar incidence to our data but high prevalence in a Caucasian population, the results may have been influenced by statistical random variation because of the small background population $(145,979$ persons $)$ and small number of NMOSD cases (6 patients). ${ }^{27}$

The superiority of the 2015 IPND criteria over 2006 criteria in identification of both seropositive and seronegative patients with NMOSD was also indicated by recent studies. ${ }^{9,34}$ Our rate of incidence correlates well with most of the previous studies, ${ }^{9,26,27}$ except one smaller study. ${ }^{24}$ It is noteworthy that the very recent incidence study from the Central Denmark Region substantiates our finding of a lower NMOSD incidence in Denmark compared to the previous Danish study from the Region of Southern Denmark. ${ }^{11,24}$

Furthermore, incidence and prevalence of seropositive patients with NMOSD reported here are in line with the nationwide study from Austria (incidence 0.046 vs 0.054; prevalence 0.72 vs 0.7$){ }^{23}$

The estimated prevalence based on ethnicity demonstrates 2.5-fold-higher prevalence in the subpopulation with Asian ancestry compared to the Caucasian, similar to the Australian cohort. ${ }^{8}$ This result should be interpreted with caution because of the small number of Asian patients in our cohort.

We found the female/male ratio consistent with other reports. ${ }^{8,9,25,26}$ The female predominance in the general population and in the seropositive population disappears in the seronegative group. ${ }^{9,35}$
The strengths of our study include (1) nationwide ascertainment from multiple sources covering a large target population, (2) diagnostic validation by an expert panel based on all clinical and paraclinical data for each case, (3) the capturerecapture analysis showed that our estimates of incidence and prevalence of NMOSD in Denmark is unlikely to be affected by a notable number of overlooked patients, (4) the majority of the patients had follow-up for many years, and (5) all clinical records were evaluated - not only from those patients who were actively followed up at their neurologic departments, but also from those who were in remission and did not require regular neurologic follow-up. This methodology allowed us to reevaluate the clinical and radiologic aspect of the disease more robustly than by relying strongly on the AQP4-Ab measurement. Of note, we removed 16 cases with false weakly positive AQP4-Ab result measured by CBA during the introduction period of this laboratory test.

Nevertheless, we may have missed cases presenting only with the very rare clinical core symptoms since we did not review patients with every type of demyelinating disorder, such as area postrema syndrome, encephalitis, or unspecified demyelinating CNS disease. Patients in whom a severe first relapse led to death may have been lost if AQP4 measurement was not conducted at the onset. The utilization of different AQP4 test methods might influence our results, although we tried to compensate for this possible weakness by reviewing all patients' clinical, laboratory, and radiologic data and a combination of different $\mathrm{Ab}$ assays. It was not possible to test all patients fulfilling the strict 2015 criteria of seronegative NMOSD for anti-MOG Abs. Still, our data can be compared to other studies since they either included patients with MOG $\mathrm{Ab}$ in their cohort ${ }^{9}$ or they did not measure it, ${ }^{8,12,24,25,27,32}$ except for the recent Japanese cohort. ${ }^{13}$

We excluded 102 cases because of insufficient data, but this is not likely to have a major effect on the validity of our results. None of the excluded patients were reported by the neurologic departments as possible NMOSD and they were not registered in the Danish National Patient Registry with NMO. In total, 55 of them had a negative AQP4 test using CBA, and in another 12 excluded cases, normal MRI was available. None of these patients had contact with any Danish neurology departments for at least 5 years until July 1,2016, which would be unexpected in a case of NMOSD, based on the severity of this condition.

In this study, we found that incidence and prevalence of NMOSD in Denmark are consistent with those of other studies in Caucasian populations. We observed no geographical clustering among the regions. Our study confirms that using the 2015 IPND criteria almost doubles the diagnostic sensitivity compared with the 2006 criteria, especially in the seronegative group. The independent reassessment of the diagnosis by an expert panel suggests that cases with mild or uncertain antiAQP4 seropositivity should be interpreted with caution and reevaluated during follow-up. 


\section{Author contributions}

V. Papp: study concept and design, analysis and interpretation of data, statistical analysis, primary author of the manuscript. Z. Illes: study concept and design, analysis and interpretation of data, critical revision of manuscript, study supervisor. M. Magyari: study concept and design, acquisition of data, revision of manuscript, study supervisor. N. Koch-Henriksen: acquisition of data, statistical analysis, analysis and interpretation of data, revision of manuscript. M. Kant: acquisition of data, analysis and interpretation of data. C.C. Pfleger: acquisition of data, analysis and interpretation of data. S.F. Roemer: acquisition of data, analysis and interpretation of data. M.B. Jensen: acquisition of data, analysis and interpretation of data. A.E. Petersen: acquisition of data, analysis and interpretation of data. H.H. Nielsen: acquisition of data, analysis and interpretation of data. L. Rosendahl: acquisition of data, analysis and interpretation of data. Z. Mezei: acquisition of data, analysis and interpretation of data. T. Christensen: analysis and interpretation of data, revision of manuscript. K. Svendsen: acquisition of data, analysis and interpretation of data. P.E. Hyldgaard Jensen: acquisition of data, analysis and interpretation of data, revision of manuscript. M.C. Lydolph: acquisition of data, analysis and interpretation of data, revision of manuscript. N. Heegaard: acquisition of data, analysis and interpretation of data. J.L. Frederiksen: acquisition of data, analysis and interpretation of data, revision of manuscript. F. Sellebjerg: acquisition of data, analysis and interpretation of data, revision of manuscript. E. Stenager: acquisition of data, analysis and interpretation of data, revision of manuscript. T. Petersen: acquisition of data, analysis and interpretation of data, revision of manuscript, study supervisor.

\section{Acknowledgment}

The authors acknowledge the contribution of all neurology departments and laboratories that provided access to the medical records and MRI and AQP4 test results. The authors thank Dr. Lars Storr, Dr. Monika Gora, Dr. Linda Locht, and Dr. Gro Dale for their assistance with data acquisition. Niels Heegaard died prior to the end of the study.

\section{Study funding}

This work was supported by the Graduate School of Health, Aarhus University (grants 1591 8355) and the Danish MS Society (grants R458-A31859, R431-A29805).

\section{Disclosure}

V. Papp reports no disclosures relevant to the manuscript. Z. Illes is a member of clinical endpoint committees in clinical trials of NMOSD but it has no conflict of interest with the current study. M. Magyari has served on the scientific advisory board for Biogen, Sanofi, Teva, Roche, Novartis, and Merck, has received honoraria for lecturing from Biogen, Merck, Novartis, Sanofi, Genzyme, and support for congress participation from Biogen, Genzyme, Teva, and Roche. N. Koch-Henriksen has received research support for congress participation from Merck. M. Kant has received support for congress participation from Biogen, Genzyme, Teva, Roche, and Novartis. C. Pfleger has received personal compensation for consulting, serving on a scientific advisory board, speaking, or other activities with Genzyme, Biogen, Roche, Novartis, and Merck. S. Roemer reports no disclosures relevant to the manuscript. M. Jensen has received personal compensation for consulting, serving on a scientific advisory board, speaking, or other activities with Teva, Roche, and Biogen. A. Petersen has received personal compensation for consulting, serving on a scientific advisory board, speaking, or other activities with Merck Serono and Roche. H. Nielsen has received personal compensation for consulting, serving on a scientific advisory board, speaking, or other activities with Sanofi Genzyme, Biogen Denmark, Novartis, and Merck. L. Rosendahl and Z. Mezei report no disclosures relevant to the manuscript. T. Christensen has received personal compensation for consulting, serving on a scientific advisory board, speaking, or other activities with Teva and Novartis. K. Svendsen, P. Jensen, M. Lydolph, and N. Heegaard report no disclosures relevant to the manuscript. J. Frederiksen has received no funding to support the presented work. She has served on scientific advisory boards for and received funding and honoraria from Biogen Idec, Merck Serono, Sanofi-Aventis, Teva, Novartis, and Almirall. She has served as advisor on preclinical development for Takeda. F. Sellebjerg has received research support from Biogen, EMD Serono, Genzyme, Lundbeck, Merck, Novartis, and Teva. E. Stenager reports no disclosures relevant to the manuscript. T. Petersen has received research support at the MS Clinic at Aarhus University Hospital from Merck, Alexion, Roche, Biogen, Novartis, and Sanofi. Go to Neurology. org/ $\mathrm{N}$ for full disclosures.

\section{Publication history}

Received by Neurology April 17, 2018. Accepted in final form August 28, 2018.

\section{References}

1. Roemer SF, Parisi JE, Lennon VA, et al. Pattern-specific loss of aquaporin-4 immunoreactivity distinguishes neuromyelitis optica from multiple sclerosis. Brain 2007; 130:1194-1205

2. Lennon PVA, Wingerchuk DM, Kryzer TJ, et al. A serum autoantibody marker of neuromyelitis optica: distinction from multiple sclerosis. Lancet 2004;364:2106-2112.

3. Wingerchuk DM, Lennon VA, Pittock SJ, Lucchinetti CF, Weinshenker BG. Revised diagnostic criteria for neuromyelitis optica. Neurology 2006;66:1485-1489.

4. Miller DH, Weinshenker BG, Filippi M, et al. Differential diagnosis of suspected multiple sclerosis: a consensus approach. Mult Scler 2008;14:1157-1174.

5. Wingerchuk DM, Lennon VA, Lucchinetti CF, Pittock SJ, Weinshenker BG. The spectrum of neuromyelitis optica. Lancet Neurol 2007;6:805-815.

6. Wingerchuk DM, Banwell B, Bennett JL, et al. International consensus diagnostic criteria for neuromyelitis optica spectrum disorders. Neurology 2015; 85:177-189.

7. Jarius S, Ruprecht $\mathrm{K}$, Kleiter I, et al. MOG-IgG in NMO and related disorders: a multicenter study of 50 patients. Part 1 : frequency, syndrome specificity, influence of disease activity, long-term course, association with AQP4-IgG, and origin. J Neuroinflammation 2016;13:279.

8. Bukhari W, Prain KM, Waters P, et al. Incidence and prevalence of NMOSD in Australia and New Zealand. J Neurol Neurosurg Psychiatry 2017;88:632-638.

9. Sepúlveda M, Aldea M, Escudero D, et al. Epidemiology of NMOSD in Catalonia: influence of the new 2015 criteria in incidence and prevalence estimates. Mult Scler Epub 2017 Oct 1.

10. Hor JY, Lim TT, Chia YK, et al. Prevalence of neuromyelitis optica spectrum disorder in the multi-ethnic Penang Island, Malaysia, and a review of worldwide prevalence. Mult Scler Relat Disord 2018;19:20-24.

11. Dale GH, Svendsen KB, Gjelstrup MC, et al. Incidence of neuromyelitis optica spectrum disorder in the Central Denmark Region. Acta Neurol Scand 2018;137: $582-588$. 
12. Eskandarieh S, Nedjat S, Azimi AR, Moghadasi AN, Sahraian MA. Neuromyelitis optica spectrum disorders in Iran. Mult Scler Relat Disord 2017;18:209-212.

13. Houzen $\mathrm{H}$, Kondo K, Niino M, et al. Prevalence and clinical features of neuromyelitis optica spectrum disorders in northern Japan. Neurology 2017;89:1995-2001.

14. Lynge E, Sandegaard JL, Rebolj M. The Danish National Patient Register. Scand J Public Health 2011;39:30-33.

15. Brønnum-Hansen H, Koch-Henriksen N, Stenager E. The Danish Multiple Sclerosis Registry. Scand J Public Health 2011;39:62-64.

16. Koch-Henriksen N, Magyari M, Laursen B. Registers of multiple sclerosis in Denmark. Acta Neurol Scand 2015;132:4-10.

17. Waters $P$, Reindl M, Saiz A, et al. Multicentre comparison of a diagnostic assay: aquaporin4 antibodies in neuromyelitis optica. J Neurol Neurosurg Psychiatry 2016;87:1005-1015.

18. Waters P, Woodhall M, O'Connor KC, et al. MOG cell-based assay detects non-MS patients with inflammatory neurologic disease. Neurol Neuroimmunol Neuroinflamm 2015;2:e89.

19. Chapman D. Some Properties of the Hypergeometric Distribution with Applications to Zoological Censuses. Berkeley: University of California Press; 1951:131-160.

20. Kitley J, Leite MI, Nakashima I, et al. Prognostic factors and disease course in aquaporin-4 antibody-positive patients with neuromyelitis optica spectrum disorder from the United Kingdom and Japan. Brain 2012;135:1834-1849.

21. Statistikbanken. Available at: statbank.dk/statbank5a/default.asp?w=12. Accessed December 1, 2017.

22. $\mathrm{Ng} \mathrm{R}$, Bernatsky S, Rahme E. Observation period effects on estimation of systemic lupus erythematosus incidence and prevalence in Quebec. J Rheumatol 2013;40:1334-1336.

23. Aboul-Enein F, Seifert-Held T, Mader S, et al. Neuromyelitis optica in Austria in 2011: to bridge the gap between neuroepidemiological research and practice in a study population of 8.4 million people. PLoS One 2013;8:e79649.

24. Asgari N, Lillevang ST, Skejoe HP, Falah M, Stenager E, Kyvik KO. A populationbased study of neuromyelitis optica in Caucasians. Neurology 2011;76:1589-1595.
25. Cossburn M, Tackley G, Baker K, et al. The prevalence of neuromyelitis optica in South East Wales. Eur J Neurol 2012;19:655-659.

26. Jacob A, Panicker J, Lythgoe D, et al. The epidemiology of neuromyelitis optica amongst adults in the Merseyside county of United Kingdom. J Neurol 2013;260: 2134-2137.

27. Flanagan EP, Cabre P, Weinshenker BG, et al. Epidemiology of aquaporin-4 autoimmunity and neuromyelitis optica spectrum. Ann Neurol 2016;79:775-783.

28. Cabrera-Gómez JA, Kurtzke JF, González-Quevedo A, Lara-Rodríguez R. An epidemiological study of neuromyelitis optica in Cuba. J Neurol 2009;256:35-44.

29. Miyamoto K, Fujihara K, Kira JI, et al. Nationwide epidemiological study of neuromyelitis optica in Japan. J Neurol Neurosurg Psychiatry 2018;89:667-668.

30. Pandit L, Kundapur R. Prevalence and patterns of demyelinating central nervous system disorders in urban Mangalore, South India. Mult Scler 2014;20:1651-1653.

31. Kashipazha D, Mohammadianinejad SE, Majdinasab N, Azizi M, Jafari M. A de scriptive study of prevalence, clinical features and other findings of neuromyelitis optica and neuromyelitis optica spectrum disorder in Khuzestan Province, Iran. Iran J Neurol 2015; 14:204-210.

32. Etemadifar M, Dashti M, Vosoughi R, Abtahi SH, Ramagopalan SV, Nasr Z. An epidemiological study of neuromyelitis optica in Isfahan. Mult Scler 2014;20. 1920-1922.

33. Houzen $\mathrm{H}$, Niino $\mathrm{M}$, Hirotani $\mathrm{M}$, et al. Increased prevalence, incidence, and female predominance of multiple sclerosis in northern Japan. J Neurol Sci 2012;323: $117-122$.

34. Uzawa A, Mori M, Uchida T, Masuda H, Ohtani R, Kuwabara S. Seronegative neuromyelitis optica spectrum disorder patients diagnosed using new diagnostic criteria. Mult Scler 2016;22:1371-1375.

35. Jarius S, Ruprecht K, Wildemann B, et al. Contrasting disease patterns in seropositive and seronegative neuromyelitis optica: a multicentre study of 175 patients. J Neuroinflammation 2012;9:14 


\section{Neurology}

\section{Nationwide prevalence and incidence study of neuromyelitis optica spectrum disorder in Denmark}

Viktoria Papp, Zsolt Illes, Melinda Magyari, et al.

Neurology 2018;91;e2265-e2275 Published Online before print November 9, 2018

DOI 10.1212/WNL.0000000000006645

This information is current as of November 9, 2018

Updated Information \& Services

References

Citations

Subspecialty Collections

Permissions \& Licensing

Reprints including high resolution figures, can be found at: http://n.neurology.org/content/91/24/e2265.full

This article cites 32 articles, 7 of which you can access for free at: http://n.neurology.org/content/91/24/e2265.full\#ref-list-1

This article has been cited by 6 HighWire-hosted articles: http://n.neurology.org/content/91/24/e2265.full\#\#otherarticles

This article, along with others on similar topics, appears in the following collection(s):

Autoimmune diseases

http://n.neurology.org/cgi/collection/autoimmune_diseases

Devic's syndrome

http://n.neurology.org/cgi/collection/devics_syndrome

Incidence studies

http://n.neurology.org/cgi/collection/incidence_studies

Prevalence studies

http://n.neurology.org/cgi/collection/prevalence_studies

Information about reproducing this article in parts (figures,tables) or in its entirety can be found online at:

http://www.neurology.org/about/about_the_journal\#permissions

Information about ordering reprints can be found online:

http://n.neurology.org/subscribers/advertise

Neurology ${ }^{\circledR}$ is the official journal of the American Academy of Neurology. Published continuously since 1951, it is now a weekly with 48 issues per year. Copyright Copyright ( 2018 The Author(s). Published by Wolters Kluwer Health, Inc. on behalf of the American Academy of Neurology.. All rights reserved. Print ISSN: 0028-3878. Online ISSN: 1526-632X.

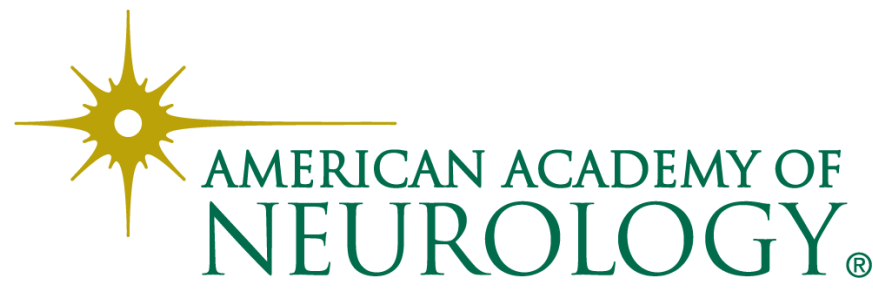

